\title{
FUZZY LOGIC BASED APPROACH FOR Automation Of EMotion Detection IN MISOPHONIA
}

\author{
Nilima Salankar, Neelu Ahuja, Sandeep Chaurasia and *,Ninni Singh \\ Centre Of Information Technology, University Of Petroleum And Energy Studies, \\ Dehradun, India \\ *Manipal Univeristy,Jaipur,India
}

\begin{abstract}
Human being mostly categories into two types, the one who follow distress cycle and other who believe on wellness cycle. Output of distress cycle is decreased productivity, decreased enjoyment and decreased intimacy, whereas output of wellness cycle is increased productivity, increased enjoyment and increased intimacy which is essential for life. Reason of distress could be anything like emotion, disease, environment, family, pain. One of the mostly unexplored areas of cause of distress is misophonia. It is a disorder related to various senses like sound, sight, smell, taste and touch. This disorder is not in DSM-V, underscoring that it is not known by psychiatric and medical communities. We have proposed an automatic fuzzy approach system for identification of intensity of emotions related to various triggers on the basis of age group.
\end{abstract}

\section{KEYWORDS}

Misophonia,Emotion,Misophonia Activation Scale,Trigger

\section{INTRODUCTION}

What is misophonia? As defined in Sound-Rage. A primer of the psychology and neurobiology of a little known anger disorder, "Misophonia comprises a unique set of symptoms, most likely attributable to neurological causes unrelated to hearing-system dysfunction. It can be described as an immediate and extreme emotional response of anger accompanied by an automatic physiological flight response and a fundamental discomfort to identifiable auditory, visual, and olfactory stimuli. The disorder disrupts daily living and can have a significant impact on all social interactions [1].The Misophonia Activation Scale (MAS-1) is intended to guide clinicians and patients in assessing the severity of a sufferer's condition. It concentrates on physical and emotional reactions to a particular misophonic trigger. It makes little reference to the status of the trigger person, i.e., as a known trigger or otherwise. Someone with misophonia may not necessarily exhibit all, or even many, of these behaviors. Also, some sufferers may experience symptoms in a different order, for instance, engaging in some "confrontational" coping behaviors before adopting more co-operative ones. MAS-1 is a work in progress and may be updated in the light of published research. 
International Journal of Computer Science \& Information Technology (IJCSIT) Vol 9, No 1, February 2017

Table 1. Misophonia Activation Scale

\begin{tabular}{|c|c|}
\hline Level & Response \\
\hline 0 & Person with misophonia hears a known trigger sound but feels no discomfort. \\
\hline 1 & $\begin{array}{l}\text { Person with misophonia is aware of the presence of a known trigger person but feels } \\
\text { no, or minimal, anticipatory anxiety. }\end{array}$ \\
\hline 2 & $\begin{array}{l}\text { Known trigger sound elicits minimal psychic discomfort, irritation or annoyance. No } \\
\text { symptoms of panic or fight or flight response. }\end{array}$ \\
\hline 3 & $\begin{array}{l}\text { Person with misophonia feels increasing levels of psychic discomfort but does not } \\
\text { engage in any physical response. Sufferer may be hyper-vigilant to audio-visual } \\
\text { stimuli. }\end{array}$ \\
\hline 4 & $\begin{array}{l}\text { Person with misophonia engages in a minimal physical response - non- } \\
\text { confrontational coping behaviors, such as asking the trigger person to stop making the } \\
\text { noise, discreetly covering one ear, or by calmly moving away from the noise. No } \\
\text { panic or fight or flight symptoms exhibited. }\end{array}$ \\
\hline 5 & $\begin{array}{l}\text { Person with misophonia adopts more confrontational coping mechanisms, such as } \\
\text { overtly covering their ears, mimicking the trigger person, engaging in other } \\
\text { echolalias, or displaying overt irritation. }\end{array}$ \\
\hline 6 & $\begin{array}{l}\text { Person with misophonia experiences substantial psychic discomfort. Symptoms of } \\
\text { panic, and a fight or flight response, begin to engage. }\end{array}$ \\
\hline 7 & $\begin{array}{l}\text { Person with misophonia experiences substantial psychic discomfort. Increasing use } \\
\text { (louder, more frequent) use of confrontational coping mechanisms. There may be } \\
\text { unwanted sexual arousal. Sufferer may re-imagine the trigger sound and visual cues } \\
\text { over and over again, sometimes for weeks, months or even years after the event. }\end{array}$ \\
\hline 8 & $\begin{array}{l}\text { Person with misophonia experiences substantial psychic discomfort. Some violence } \\
\text { ideation. }\end{array}$ \\
\hline 9 & $\begin{array}{l}\text { Panic/rage reaction in full swing. Conscious decision not to use violence on trigger } \\
\text { person. Actual flight from vicinity of noise and/or use of physical violence on an } \\
\text { inanimate object. Panic, anger or severe irritation may be manifest in sufferer's } \\
\text { demeanour. }\end{array}$ \\
\hline 10 & $\begin{array}{l}\text { Actual use of physical violence on a person or animal (i.e., a household pet). } \\
\text { Violence may be inflicted on self (self-harming). }\end{array}$ \\
\hline
\end{tabular}

\section{ONLINE SURVEY}

On July 8th, 2013, a group of people who suffer from misophonia, self-identified as a "group of amateur researchers," compiled a survey of just over 120 questions with the hope of generating a data base of information. The survey was publicized to misophonia communities on at least three social media group sites, yahoo groups (Selective Sound Sensitivity Yahoo group), reddit ( $\mathrm{r} /$ misophonia on reddit), and tumblr (misophoniasupport.tumblr.com). As an online survey with no log-in or opt-in requirements, it was an open survey available to the general public. Thus, for the following analysis, it is assumed that the people who answered the survey are misophonia sufferers.

\section{TRAINED DATASET GENERATION ON THE BASIS OF ONLINE SURVEY}

We have observed 521 samples, 395 females and 126 males in the age group of 12-50.For better understanding of generation of emotion pattern we have sub-divided age as per following: 


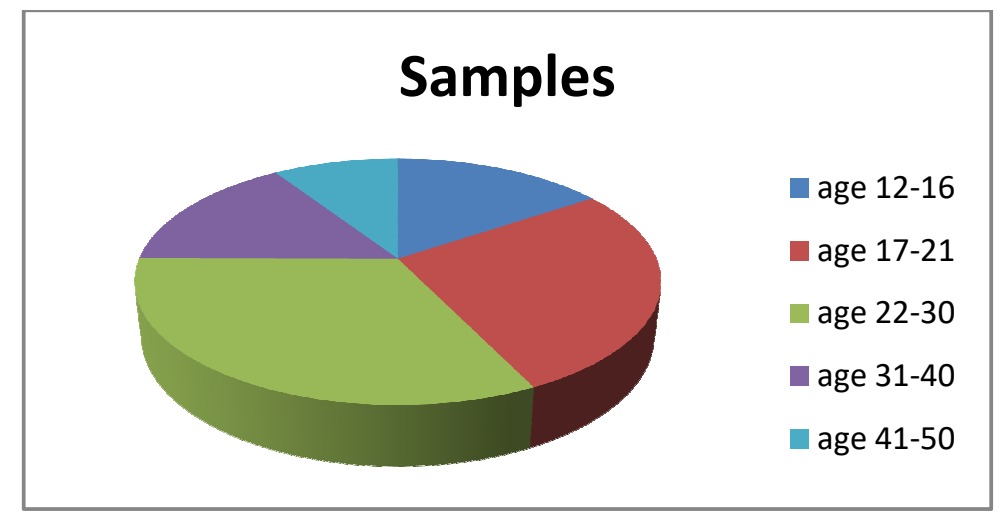

Figure 1. No of samples and age group

Questionnaire asked in an online survey are related to whether emotion get triggered or not, if reply of question is yes we have converted it into 1 and if reply is no we have converted it into 0.Total 27 triggers which are the cause for activation of sound disorder we have included and rest we have ignored. We have used rapid miner for the computation of statistics of dataset.

Triggers at the primary level are hearing, sight, any specific taste, any specific smell or any specific touch. Related to hearing triggers associated are Clipping Nails, Brushing Teeth, Eating with noise, Sniffing, Talking, Sneezing, Yawning, Sighing, Walking, Chewing, Laughing, Snoring, Whisteling, Ticking clocks, Windshield wipers, Barking Dogs, Rocking chairs, Tapping pen,whispering,Noisy Neighbour,TV/Radio, Any specific sound not listed. Related to sight triggers associated are Clipping Nails, Brushingteeth, Eating with noise, Sniffing, Talking, Sneezing,Yawning,Sighing,Walking,Chewing,Laughing,Snoring,Whisteling,Ticking clocks, Windshield wipers, Barking Dogs, Rocking chairs, Tapping pen,whispering,Noisy Neighour,TV/Radio, Blinking Light, Any specific sight not listed. 
International Journal of Computer Science \& Information Technology (IJCSIT) Vol 9, No 1, February 2017

\begin{tabular}{|c|c|c|c|c|c|c|}
\hline Age & Integer & o & ${ }_{12}^{\text {Min }}$ & ${ }_{16}^{\operatorname{Max}}$ & $\begin{array}{l}\text { Averace } \\
15\end{array}$ & $\begin{array}{l}\text { Devisation } \\
1.095\end{array}$ \\
\hline Gender & Polynominal & $\circ$ & Male (11) & & $\begin{array}{l}\text { Most } \\
\text { Female (20) }\end{array}$ & $\begin{array}{l}\text { values } \\
\text { Female (20), Male (11) }\end{array}$ \\
\hline Hearing & $B$ Binominal & 0 & $\begin{array}{l}\text { Lesst } \\
\mathbf{0}(1)\end{array}$ & & $\begin{array}{l}\text { Most } \\
1(30)\end{array}$ & $\begin{array}{l}\text { valuos } \\
1(30), 0(1)\end{array}$ \\
\hline sight & Binominal & 0 & $\begin{array}{l}\text { Least } \\
\text { o (14) }\end{array}$ & & $\begin{array}{l}\text { Most } \\
1(17)\end{array}$ & $\begin{array}{l}\text { walues } \\
1(17), 0(14)\end{array}$ \\
\hline smell & Binominal & 0 & $\begin{array}{l}\text { Lesst } \\
1 \text { (3) }\end{array}$ & & $\begin{array}{l}\text { Most } \\
0(28)\end{array}$ & Walues 1 (3) \\
\hline Taste & Einominal & 0 & $\begin{array}{l}\text { Lesst } \\
1(1)\end{array}$ & & $\begin{array}{l}\text { Most } \\
0(30)\end{array}$ & $\begin{array}{l}\text { values } \\
0(30), 1(1)\end{array}$ \\
\hline Touch & Binominal & 0 & $\begin{array}{l}\text { Least } \\
1(8)\end{array}$ & & $\begin{array}{l}\text { Most } \\
\mathrm{D}(23)\end{array}$ & $0(23)=1$ (8) \\
\hline Clipping Nails & Binominal & 0 & $\begin{array}{l}\text { Least } \\
1(2)\end{array}$ & & $\begin{array}{l}\text { Most } \\
0(29)\end{array}$ & $\begin{array}{l}\text { Walues } \\
0(29), 1(2)\end{array}$ \\
\hline Brushing Teeth & $B$ Binominal & 0 & $\begin{array}{l}\text { Loost } \\
1(2)\end{array}$ & & $\begin{array}{l}\text { Moost } \\
0(29)\end{array}$ & $0(29), 1(2)$ \\
\hline Eating & Bnominal & 0 & $\begin{array}{l}\text { Least } \\
\mathrm{O}(4)\end{array}$ & & $\begin{array}{l}\text { Most } \\
1(27)\end{array}$ & $\begin{array}{l}\text { values } \\
1(27), 0(4)\end{array}$ \\
\hline sniffing & $B$ Binominal & 0 & $\begin{array}{l}\text { Loast } \\
1(12)\end{array}$ & & $\begin{array}{l}\text { Most } \\
\text { O (19) }\end{array}$ & $\begin{array}{l}\text { Values } \\
0(19), 1(12)\end{array}$ \\
\hline Talkıng & Binominal & 0 & $\begin{array}{l}\text { Least } \\
1 \text { (3) }\end{array}$ & & $\begin{array}{l}\text { Most } \\
0(28)\end{array}$ & $\begin{array}{l}\text { Values } \\
\text { O (28). } 1 \text { (3) }\end{array}$ \\
\hline Sneezing & Binominal & 0 & $\begin{array}{l}\text { Least } \\
1(4)\end{array}$ & & $\begin{array}{l}\text { Moost } \\
0(27)\end{array}$ & $0(27), 1(4)$ \\
\hline rawning & Binominal & o & $\begin{array}{l}\text { Lesst } \\
1 \text { (3) }\end{array}$ & & $\begin{array}{l}\text { Most } \\
0(28)\end{array}$ & $\begin{array}{l}\text { values } \\
0(28) .1 \text { (3) }\end{array}$ \\
\hline Sighing & Einominal & 0 & $\begin{array}{l}\text { Leost } \\
1(3)\end{array}$ & & $\begin{array}{l}\text { Moot } \\
\text { O (28) }\end{array}$ & $\begin{array}{l}\text { Values } \\
0(28), 1(3)\end{array}$ \\
\hline walking & Binominal & 0 & $\begin{array}{l}\text { Least } \\
\text { o (31) }\end{array}$ & & $\begin{array}{l}\text { Most } \\
\text { O (31) }\end{array}$ & $\begin{array}{l}\text { Values } \\
\text { O (31) }\end{array}$ \\
\hline Chewing & Binominal & 0 & $\begin{array}{l}\text { Lesst } \\
\mathbf{O}(7)\end{array}$ & & 1 (24) & $1(24), 0(7)$ \\
\hline Laughing & Binominal & 0 & $\begin{array}{l}\text { Least } \\
\text { o (31) }\end{array}$ & & $\begin{array}{l}\text { Most } \\
\text { O (31) }\end{array}$ & $\begin{array}{l}\text { values } \\
\text { O(31) }\end{array}$ \\
\hline soring & Binominal & 0 & $\begin{array}{l}\text { Loost } \\
1(11)\end{array}$ & & $\begin{array}{l}\text { Most } \\
\text { O (20) }\end{array}$ & $\begin{array}{l}\text { values } \\
0(20), 1(11)\end{array}$ \\
\hline whistellng & Binominal & 0 & $\begin{array}{l}\text { Least } \\
1(2)\end{array}$ & & $\begin{array}{l}\text { Most } \\
\text { o (29) }\end{array}$ & $\begin{array}{l}\text { Values } \\
0(29), 1(2)\end{array}$ \\
\hline Ticking Clacks & $B$ Einominal & 0 & $\begin{array}{l}\text { Least } \\
1(3)\end{array}$ & & $\begin{array}{l}\text { Most } \\
\text { O (28) }\end{array}$ & $0(28)=1$ (3) \\
\hline Blinking Lights & Binominal & 0 & $\begin{array}{l}\text { Least } \\
0 \text { (31) }\end{array}$ & & $\begin{array}{l}\text { Most } \\
\text { O (31) }\end{array}$ & $\begin{array}{l}\text { Values } \\
\text { O (31) }\end{array}$ \\
\hline Windshield Wipers & Binominal & 0 & $\begin{array}{l}\text { Least } \\
\mathbf{0}(31)\end{array}$ & & $\begin{array}{l}\text { Most } \\
\text { O (31) }\end{array}$ & $\begin{array}{l}\text { Walues } \\
\text { O(31) }\end{array}$ \\
\hline Barking dogs & Binominal & 0 & $\begin{array}{l}\text { Least } \\
1(2)\end{array}$ & & $\begin{array}{l}\text { Most } \\
\text { O (29) }\end{array}$ & $\begin{array}{l}\text { Values } \\
0(29), 1(2)\end{array}$ \\
\hline Rocking chairs & Binominal & 0 & $\begin{array}{l}\text { Least } \\
\text { o (31) }\end{array}$ & & $\begin{array}{l}\text { Most } \\
\text { o (31) }\end{array}$ & $\begin{array}{l}\text { Values } \\
\text { O (31) }\end{array}$ \\
\hline Tapping pen & Binominal & 0 & $\begin{array}{l}\text { Leost } \\
1(4)\end{array}$ & & $\begin{array}{l}\text { Most } \\
0(27)\end{array}$ & $\begin{array}{l}\text { Values } \\
0(27), 1(4)\end{array}$ \\
\hline whispering & Eınominal & 0 & $\begin{array}{l}\text { Least } \\
1(2)\end{array}$ & & $\begin{array}{l}\text { Most } \\
\text { o (29) }\end{array}$ & $\begin{array}{l}\text { Values } \\
0(29), 1(2)\end{array}$ \\
\hline Oisy neighbour & Binominal & 0 & $\begin{array}{l}\text { Leset } \\
1(2)\end{array}$ & & $\begin{array}{l}\text { Most } \\
\text { O (29) }\end{array}$ & $0(29), 1(2)$ \\
\hline TV/Radio sound & Einominal & 0 & $\begin{array}{l}\text { Least } \\
\text { o (15) }\end{array}$ & & $\begin{array}{l}\text { Most } \\
1(16)\end{array}$ & $\begin{array}{l}\text { values } \\
1(16), 0(15)\end{array}$ \\
\hline Total & Integer & 0 & $\begin{array}{l}\text { Min } \\
\text { o }\end{array}$ & $\begin{array}{l}\operatorname{Max} \\
8\end{array}$ & $\begin{array}{l}\text { Aversoe } \\
5.839\end{array}$ & $\begin{array}{l}\text { Deviation } \\
1.753\end{array}$ \\
\hline Rank-1 & Polynominal & 0 & $\begin{array}{l}\text { Lesat } \\
H(4)\end{array}$ & & $\begin{array}{l}\text { Most } \\
\text { D (12) }\end{array}$ & $\begin{array}{l}\text { Values } \\
\text { D (12), A (5), ... [3 more] }\end{array}$ \\
\hline Rank-2 & B Polynominal & o & $\begin{array}{l}\text { Lesst } \\
H(2)\end{array}$ & & $\begin{array}{l}\text { Most } \\
\text { A (16) }\end{array}$ & $\begin{array}{l}\text { values } \\
\text { A (16), D (7), ... [3 more] }\end{array}$ \\
\hline Rank-3 & Dolynominal & o & $\begin{array}{l}\text { Loset } \\
F(2)\end{array}$ & & $\begin{array}{l}\text { Mot } \\
P(8)\end{array}$ & $P(8), R(8), \ldots[4$ more $]$ \\
\hline Rank-4 & Solynominal & ${ }^{\circ}$ & $\begin{array}{l}\text { Least } \\
F(2)\end{array}$ & & $\begin{array}{l}\text { Mast } \\
H(a)\end{array}$ & $\begin{array}{l}\text { Values } \\
H(8), A(7), \ldots[4 \text { more }]\end{array}$ \\
\hline
\end{tabular}

Figure 2. Emotion pattern and triggers

We have sub divided all the samples in the table 1on the basis of triggers responsible for emotion arousal. The minimum number of triggers responsible for generation of emotions lies in the range $0-8$, average no of triggers lie in the range of 9-13 and most number of triggers responsible is 1427. 
International Journal of Computer Science \& Information Technology (IJCSIT) Vol 9, No 1, February 2017

Table 2.Co-relation of Emotion patterns and No. of triggers

\begin{tabular}{|l|l|l|l|l|}
\hline No of Triggers & Age Group & $\begin{array}{l}\text { No of samples } \\
\text { observed }\end{array}$ & $\begin{array}{l}\text { Most aroused } \\
\text { emotion pattern }\end{array}$ & $\begin{array}{l}\text { Least aroused } \\
\text { emotion pattern }\end{array}$ \\
\hline $0-8$ & $12-16$ & 21 & DAPH & HHFF \\
\hline & $17-21$ & 48 & AAHD & GGFA \\
\hline & $22-30$ & 75 & DAHH & GGGF \\
\hline & $31-40$ & 29 & AAHR & HHPF \\
\hline & $41-50$ & 18 & ARAD & HPRG \\
\hline $9-13$ & $12-16$ & 37 & AARH & FFFP \\
\hline & $17-21$ & 58 & ARAH & HGGF \\
\hline & $22-30$ & 56 & ARHH & GPGF \\
\hline & $31-40$ & 34 & RAHH & HHRF \\
\hline $14-27$ & $41-50$ & 19 & ADRH & RPPF \\
\hline & $12-16$ & 13 & DAAH & PHPR \\
\hline & $17-21$ & 36 & ARHH & GGFP \\
\hline & $22-30$ & 37 & ADHD & PFGG \\
\hline & $31-40$ & 19 & AADH & FGRF \\
\hline & $41-50$ & 11 & ADDH & RAPA \\
\hline
\end{tabular}

\subsection{ANALYSIS}

From online survey intensity of emotion is directly proportional to age and summation of no of triggers responsible. We have observed generated pattern of an emotions on the basis of level 0level 4, i.e. rank - 0 to rank - 4. In mostly aroused emotion irrespective of age, disgust and anger are two prominent emotions. From analysis for different age group and different number of triggers, pattern generated is unique. The emotion which is active in mostly aroused pattern is inactive in least aroused pattern and if it is available then it is at the rank-4 not at the prominent position. Prominent emotions are Disgust(D), Anger(A), Panic(P), Hate(H), Rage(R), Fear(F), Guilt(G)

\section{RELATED WORK}

Prof. L.A.Zadeh has invented the concept of fuzzy logic in 1964 and presented his first paper in 1965 on fuzzy sets. Later Assilian and E.Mamdani developed fuzzy inference approach in 1974, which offers a very reasonable handling of imprecise data and solving of different real world problems using systemic rule dependent concept. Another parallel approach was developed by Sugeno, which is equally popular and used widely as an alternate approach for inferencing. Fuzzy logic has been very widely used in design of decision making systems in wide range of fields, particularly scientific, such as medicine, engineering, social sciences, etc. There have been hybrid systems developed in recent past with techniques of neural networks, neural learning, being utilized in enhancing and fine tuning the decision making ability of fuzzy systems.

The concept of fuzzy logic is very popular in decision areas of computer sciences, especially, where the data is uncertain and unconventional. The uncertain data collected in real time scenarios can be fed into fuzzy logic model to obtain meaningful conclusions which can form a firm base to future work carried out by practitioners of the concerned domain. The choice of 
fuzzy logic is due to the reason of its suitability to work with imprecise data. Additionally, it offers easy understanding of the utilized process of reasoning and decision making.

Ashish Patel [2] proposed a self-regulating system by utilizing a self-organizing rule-based fuzzy system. The system having inherent ability to handle the uncertainty and having an add-on mechanism that refuses to work with imperfect data. The system generally asks five symptoms to the user i.e. Daytime symptoms, Night time symptoms, Peak Expiratory Flow rate variability, Saturation of oxygen and peak Expiratory Flow rate and by following fuzzy rules it comes up with one result of the Asthmatic syndrome.

Wang and Palade [3] proposed a system for diagnosing Lung Cancer by utilizing Multi-Objective Evolutionary Algorithm based Interpretable fuzzy. This system analyzes biomedical data-set, i.e. proteomics mass, gene expression and by following fuzzy rules it come up to a conclusion.

Indah Soesanti [4] proposed a system for diagnosing MRI (Magnetic Resonance Imaging) segmentation of brain images by utilizing optimized fuzzy logic. The outcomes of the system shows that the system efficiently segments the normal brain MRI image, brain image MRI with spatial information and the brain image MRI that contained tumor.

Benecchi [5] proposed a system for diagnosing Menigioma by integrating Fuzzy C-Mean with region growing techniques. The outcome of the system shows that the system effectively detects tumors in the images from the patient's images that contained Menigioma.

Samar Samir Mohamed [6] proposed a system for diagnosing meningitis by utilizing fuzzy cognitive map. The outcomes of the system show that the system effectively detects membranes surrounding the brain and spinal cord. Physicians generally used this tool for precise diagnosis.

\subsection{Proposed WorK}

In a real-time scenario, the vagueness and imprecision of a statement can be interpreted through the fuzzy approach. In the present work the data concerning response of the Misophonia sufferers to various triggers under categories of senses, such as, sight, touch, hearing, taste and smell have been collected. This response is further represented in form of pattern of emotions, which are manifested in the misophonia patients. Since this is a pioneering work, with online survey data utilized for generation of the trained data set, the work has been extended to the design and development of an expert system built using fuzzy inference mechanism.

The fuzzy inference expert system has been modeled using fuzzy sets, fuzzy rules, linguistic variables and fuzzy membership functions for input and output. Based on the online survey sample data available, the most probable response of the misophonic individual, in the form of triggered emotional pattern is obtained. The learnings in terms of causal category and the triggers, and resultant emotional pattern have been built into the knowledge-base of the built system, for systematic decision making and recommendation.

The system accepts the input regarding age, trigger category and the specific trigger, and predicts as output the response which is most probable resultant emotional pattern. The system uses fuzzy sets and 'if-then' rules relevant to fuzzy sets, to make decisions about incomplete or vague 
information available to it. In this work, the mamdani fuzzy inference algorithm is used to determine the output.

The FIS (Fuzzy Inference System) executes in three major steps- Fuzzification, Inference and Defuzzification. Defuzzification provides the information in terms of crisp values and the same can be used to predict the result.

The first part of the work involves determination of degree of membership for crisp input variables. The next aspect is inferencing, involving evaluation of fuzzy rules and producing of the output for each of the rules. Finally, the resulting fuzzy output is converted back into crisp values through the defuzzification process. The section 4.2 describes the fuzzy system in detail

\subsection{DeSIGN METHODOLOGY}

For a given individual, the basic details such as 'age' and 'name' are accepted by the system, after which it proceeds with the acceptance of fuzzy input values, inferences through its knowledge-base and then presents the output. Five linguistic variables namely, the senses such as sight, hearing, touch, smell and taste have been used as input variables. Each of these variables can be further characterized by specific behavior that is the trigger for influencing the onset of misophonic symptoms, which is actually, the emotional response of the individual, the misophonic sufferer. Therefore, the output parameter is the emotional pattern response. On the basis of input and output variables about 22 fuzzy rules have been defined. Each input has two membership functions and output has fifteen membership functions. The 'flint tool kit' within WinProlog environment has been used to develop the system.

Each of the five linguistic variables is defined by two input membership functions namely, 'yes' and 'no'. The system accepts the values entered by the user for the five senses, indicating whether or not, the specific sense triggers misophonic response in a given person. For the input variables, 'sight' and 'hearing', a positive response, leads to further probing, in terms of the specific behaviors or actions, such as 'clipping nails', 'windshield wiper movement', that are responsible to trigger misophonic response. The system accepts the input, each time incrementing by one, a counter, named 'score', for every 'yes' input gathered. This is indicative of the severity of misophonia for a given individual, as the larger the score, the more is the intensity of the disorder.

Age of the individual has been taken as another input variable, covering a range of 12 to 50, with five fuzzy sets made for sub-ranges in it. A fuzzy set 'child' has age range of 12 to 16, 'fuzzy set 'teen' has age range of 15 to 21 , fuzzy set 'adult' has age range of 20 to 30, fuzzy set 'average' has age range 29 to 40, and fuzzy set 'old' has age range 39 to 50. The age-wise distribution of output provides perspective of specific influence of age of an individual on the response of the individual.

The score ranges have been mapped to emotional response patterns. A fuzzy matrix has been made with age in first and score in second columns respectively, implying the resultant emotional pattern response in the third (output) column. Thus, the system accepts the details, executes the fuzzy rules and displays the emotional response pattern, as a recommendation.

The proposed system facilitates the misophonia interest groups, medical practitioners, social workers, and even misophonia sufferers themselves to identify, understand, investigate and remediate the disorder. 
The section below presents a sample of source code depicting design of fuzzy sets, input and output variables, membership functions and fuzzy rules.

The source code of the proposed system is included in Annexure 1, appended at the end of this paper.

The implementation of the proposed system elucidating work flow has been detailed in the section below.

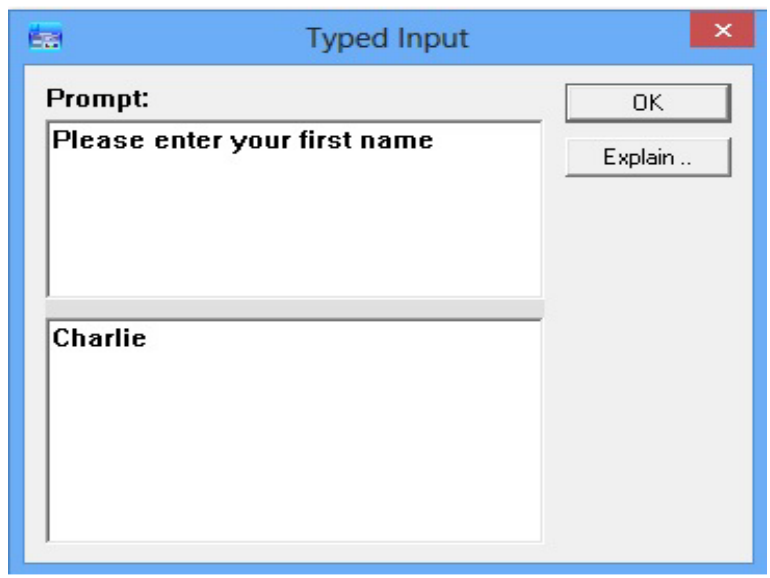

Figure 3. Requesting input (Name)

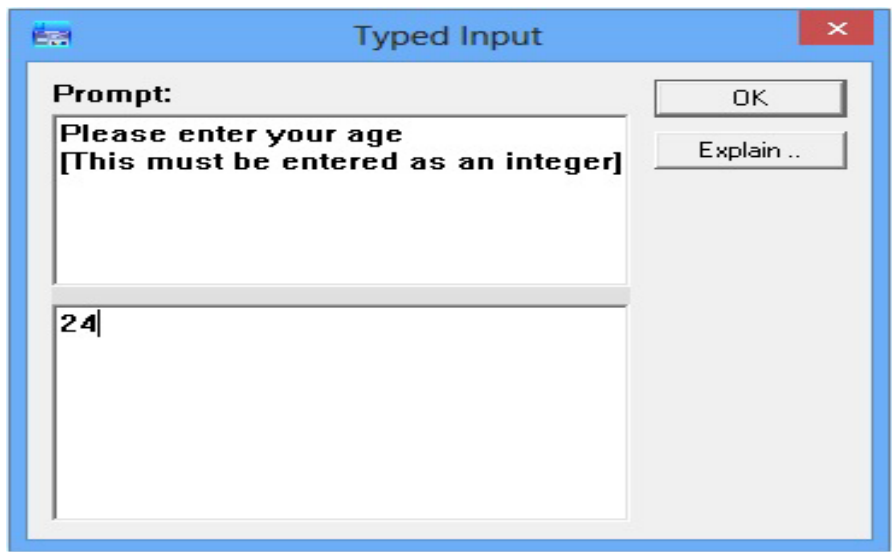

Figure 4. Requesting input (Age) 
International Journal of Computer Science \& Information Technology (IJCSIT) Vol 9, No 1, February 2017

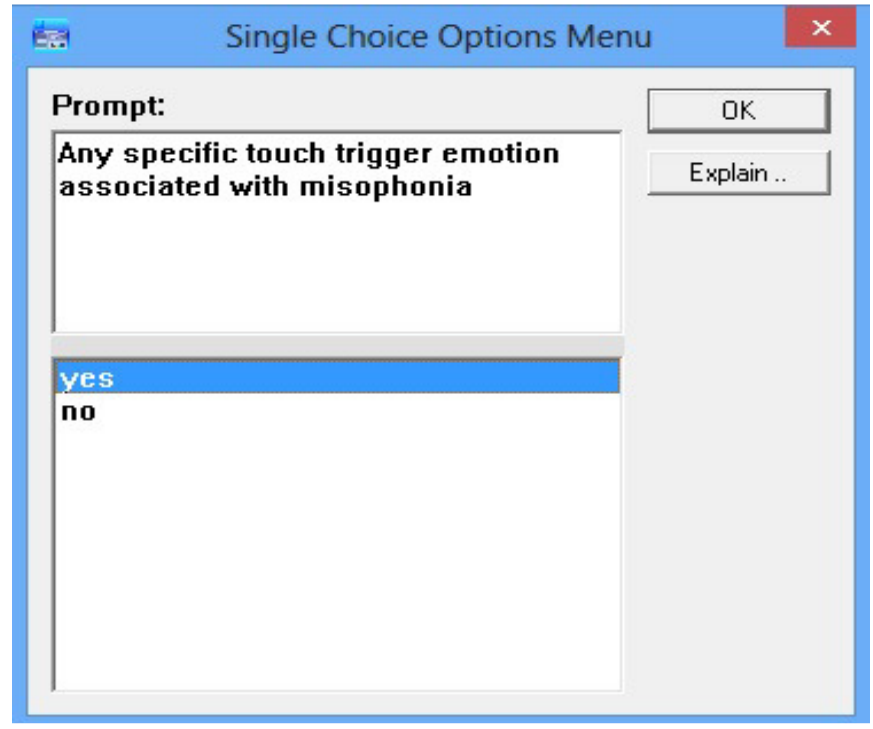

Figure 5. Requesting input(Touch Trigger)

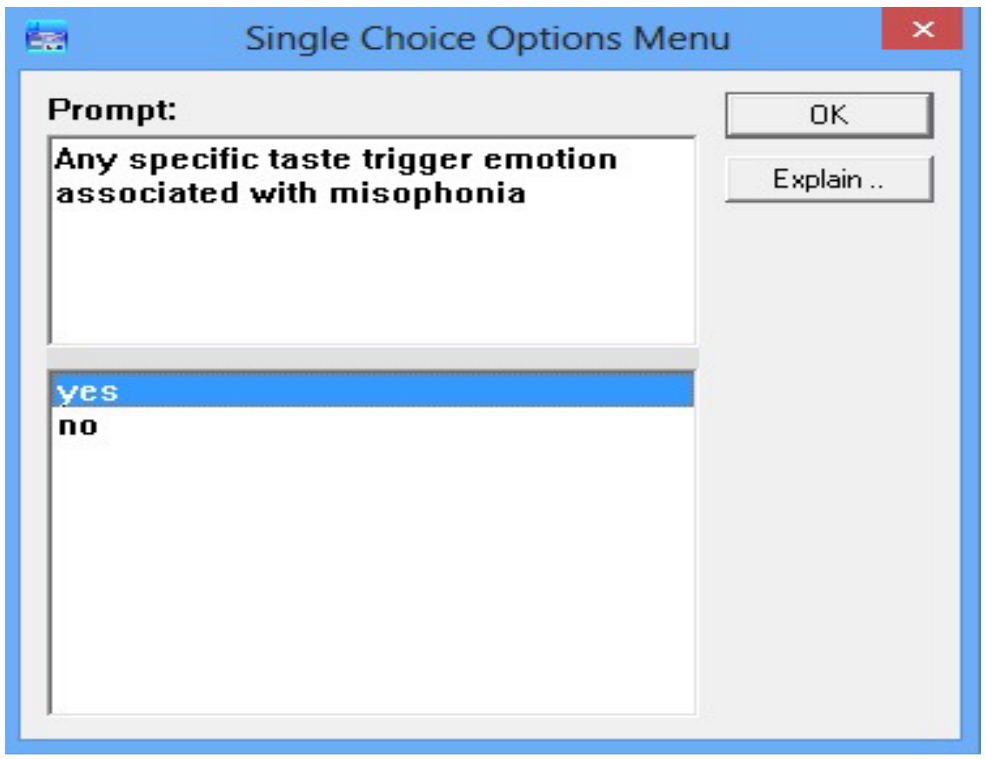

Figure 6.Requestinginput (TasteTrigger) 
International Journal of Computer Science \& Information Technology (IJCSIT) Vol 9, No 1, February 2017

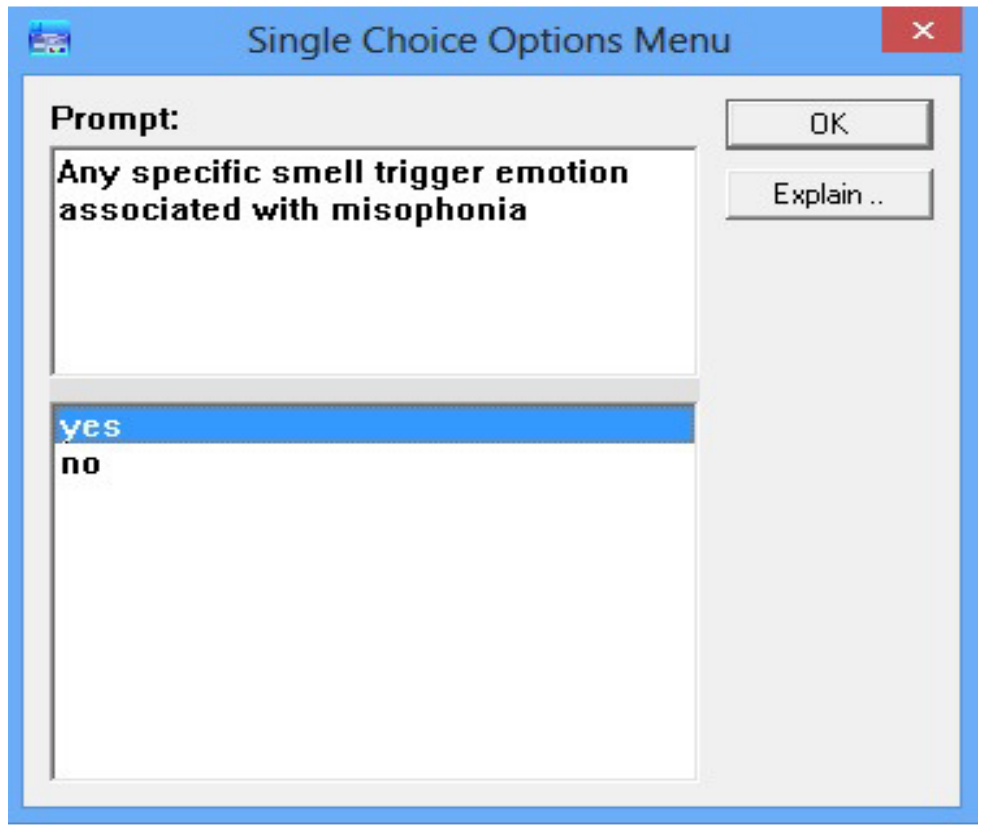

Figure 7. Requesting input (Smell Trigger)

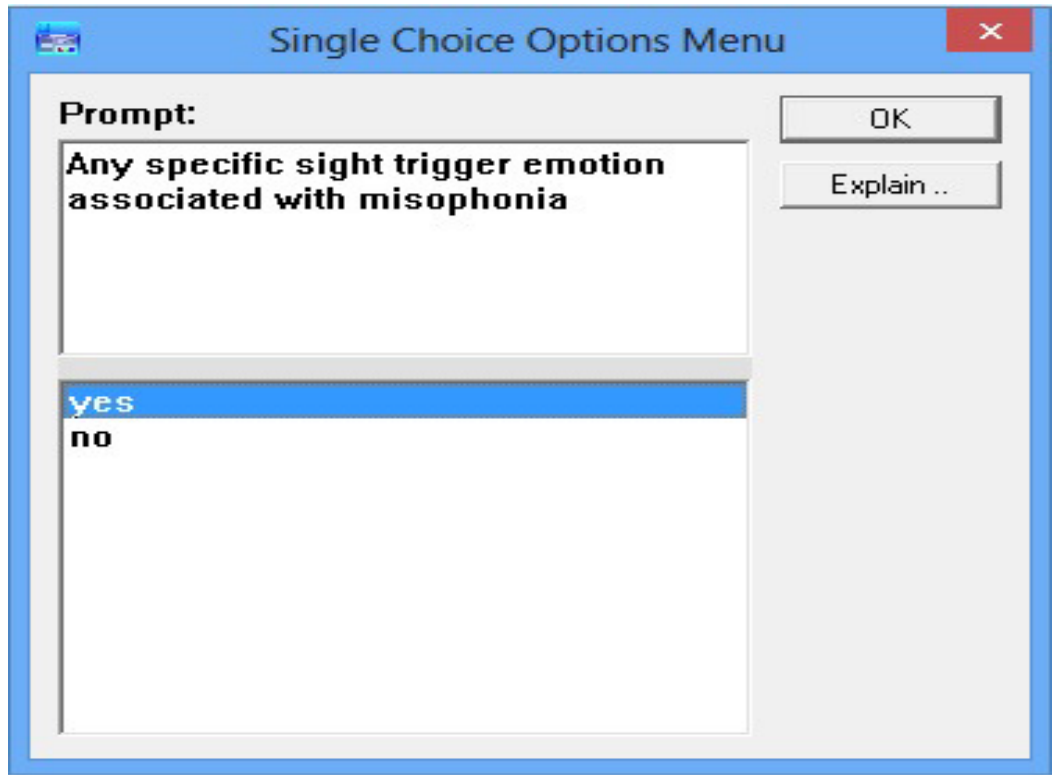

Figure 8. Requesting input (Sight Trigger) 
International Journal of Computer Science \& Information Technology (IJCSIT) Vol 9, No 1, February 2017

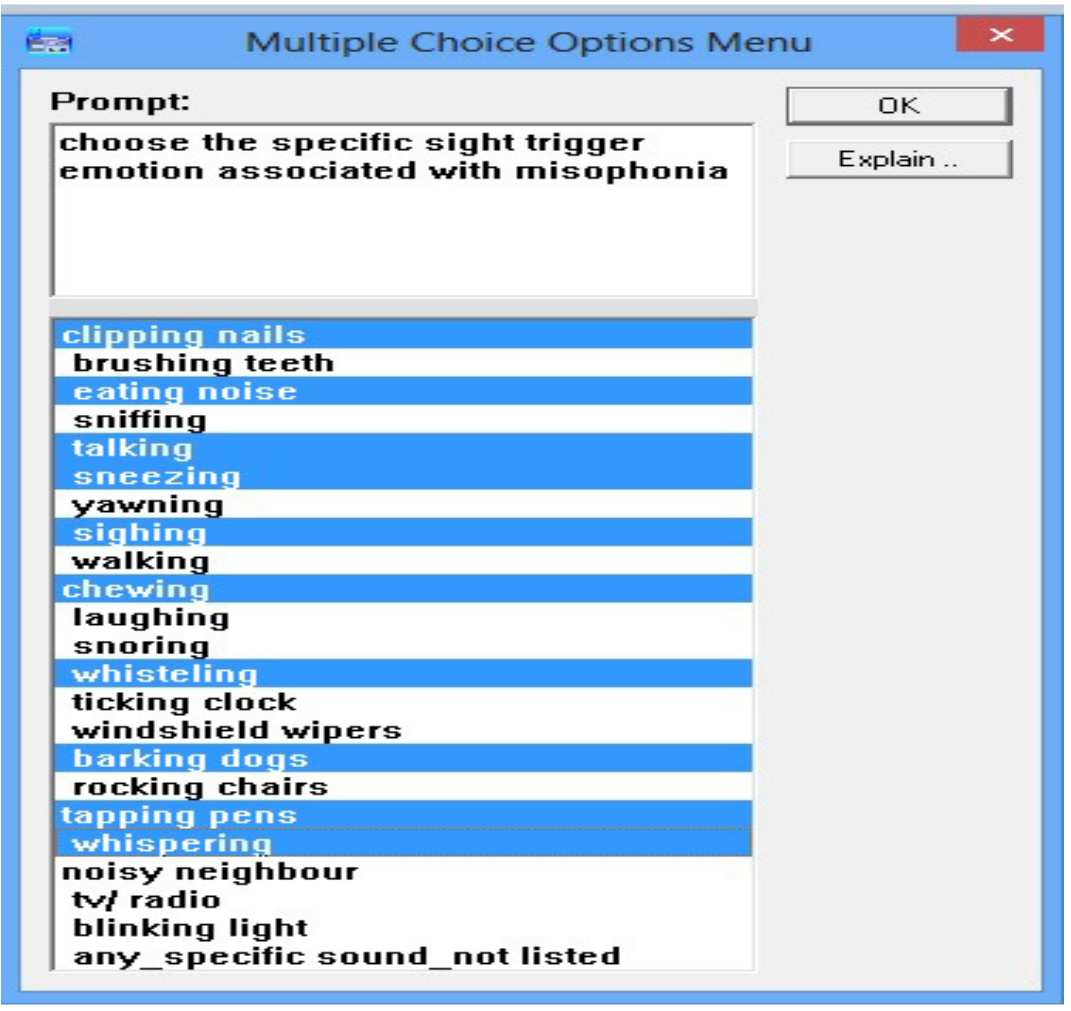

Figure 9. Requesting to choose the specific Cause for Sight Triggering

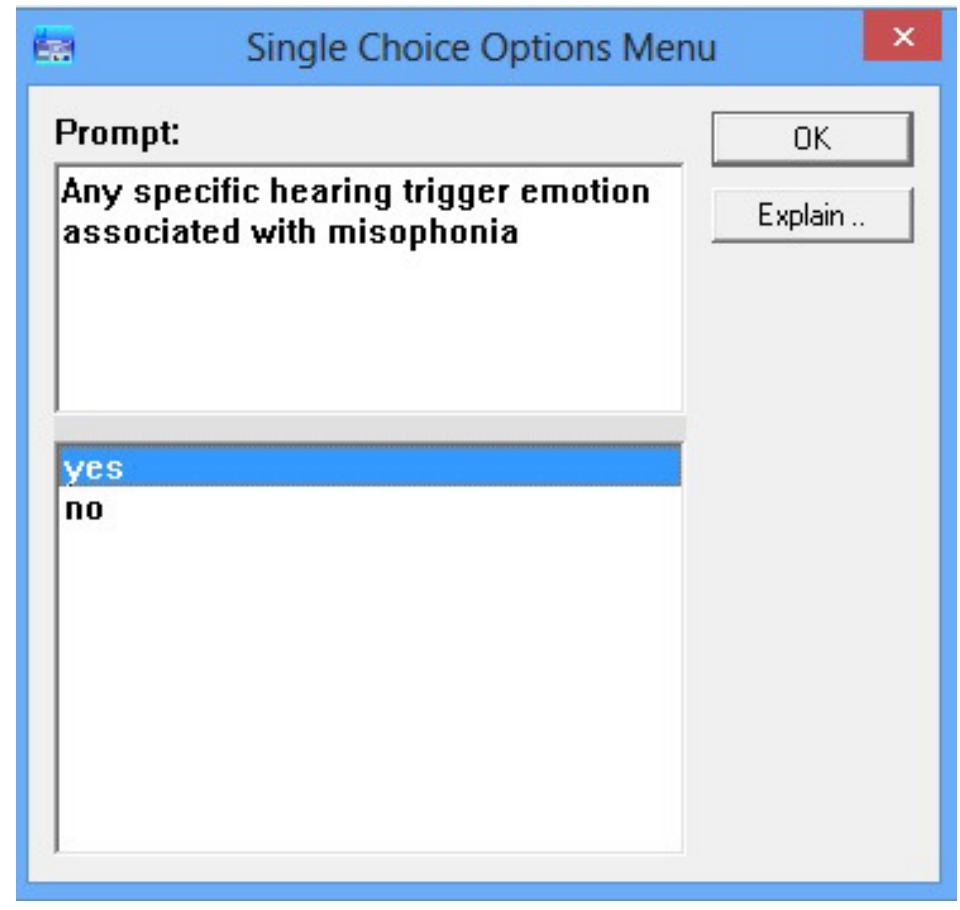

Figure 10. Requesting input (Hearing Trigger) 
International Journal of Computer Science \& Information Technology (IJCSIT) Vol 9, No 1, February 2017

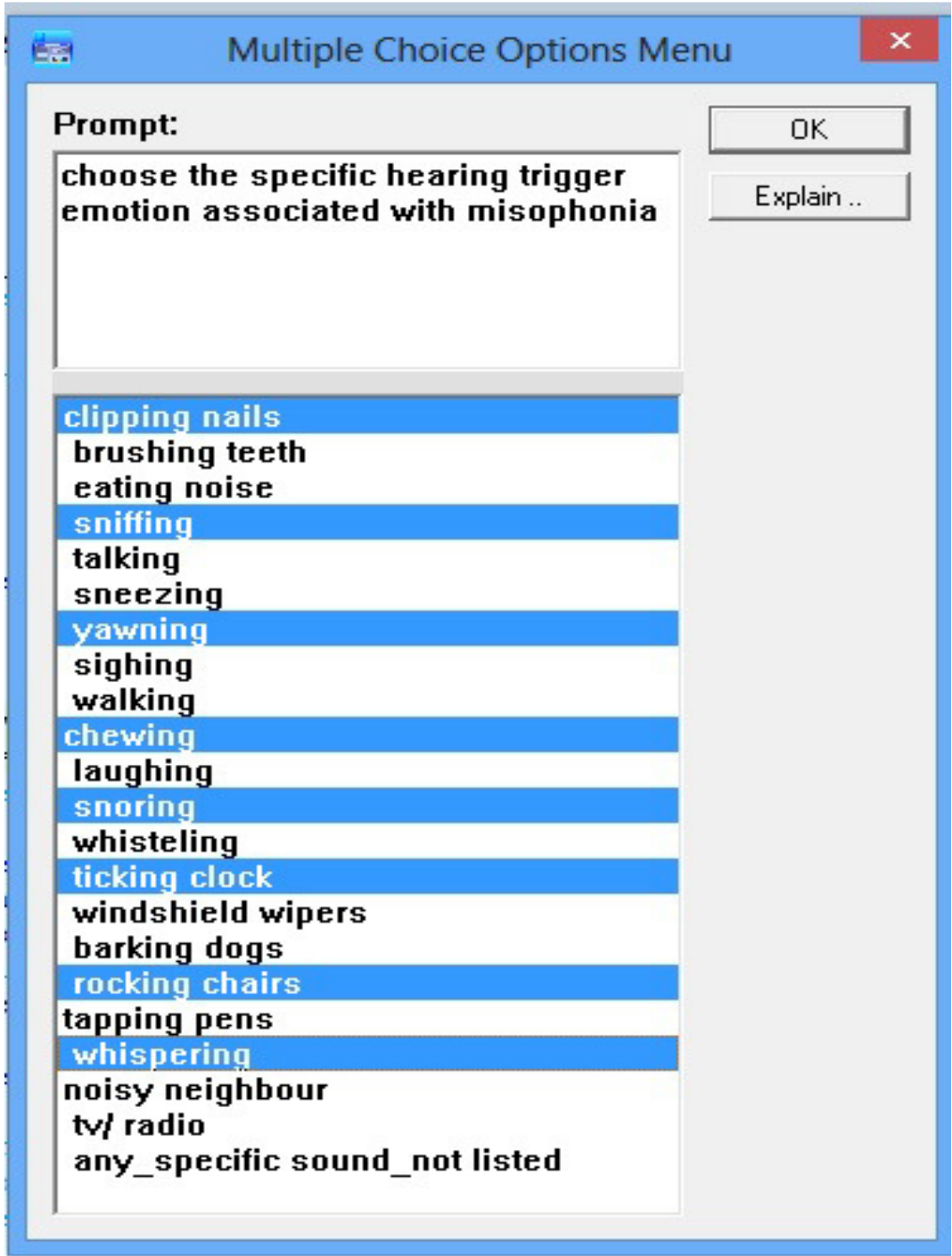

Figure 11. Requesting to choose the specific Cause for Hearing Triggering 


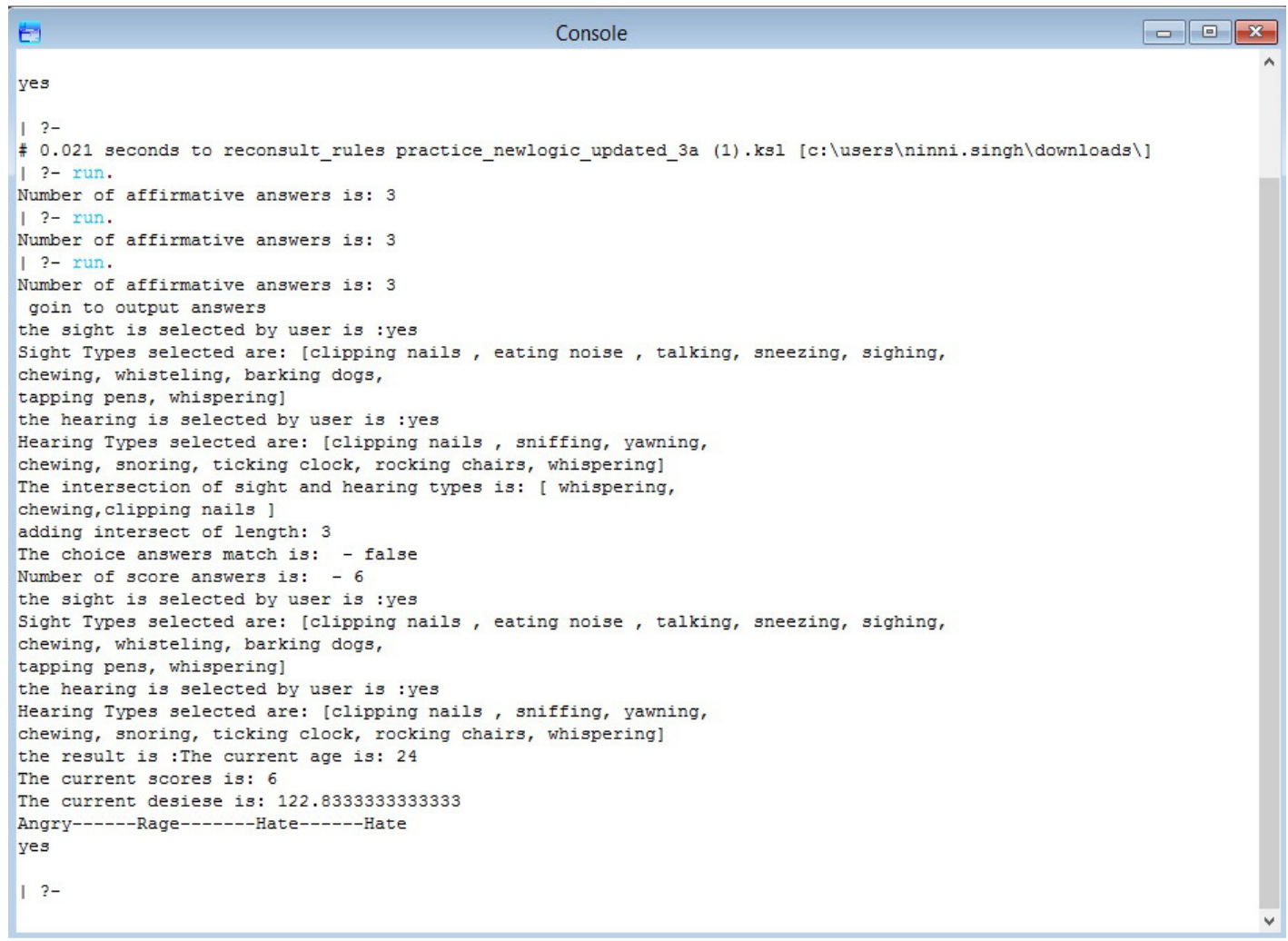

Figure 12. Identification of Disease by the System on the basis of previously asked questions

\section{Conclusion}

We have drawn an inference from an online survey and proposed fuzzy logic based methodology for early identification of symptoms associated with misophonia.

\section{REFERENCES}

[1] Krauthamer,Judith T.(2014).Descriptive Statistics Of Misophonia Retrieved Online From Www.Sound-Rage.Com

[2] Ashish Patel, Jyotsna Choubey, Shailendra K Gupta, M. K. Verma, Rajendra Prasad, Qamar Rahman, "Decision Support System For The Diagnosis Of Asthma Severity Using Fuzzy Logic ", In IMECS 2012,Pp. No.142-147.

[3] Zhenyu Wang, Vasile Palade "'Building Interpretable Fuzzy Models For High Dimensional Data Analysis In Cancer Diagnosis", In IEEE International Conference On Bioinformatics And Biomedicine 2010 Hong Kong, P. R. China. 18-21 December 2010.

[4] Indah Soesanti, Adhisusanto, Thomas Sri Widodo, Maesadji Tjokronagoro , "Optimized Fuzzy Logic Application For MRI Brain Images Segmentation" ,In International Journal Of Computer Science \& Information Technology (IJCSIT) Vol 3, No 5, Oct 2011.

[5] Benecchi L, "Neuro-Fuzzy System For Prostate Cancer Diagnosis", Urology. 2006 August.

[6] Samar Samir Mohamed,J. M. Li, M. M. A. Salama, G. H. Freeman,H. R. Tizhoosh,A. Fensterand K. Rizkalla, "An Automated Neural-Fuzzy Approach To Malignant Tumorlocalization In 2D Ultrasonic Images Of The Prostate", In Journal Of Digital Imaging, Vol 24, No 3 June, 2011. 


\section{ANNEXURE I}

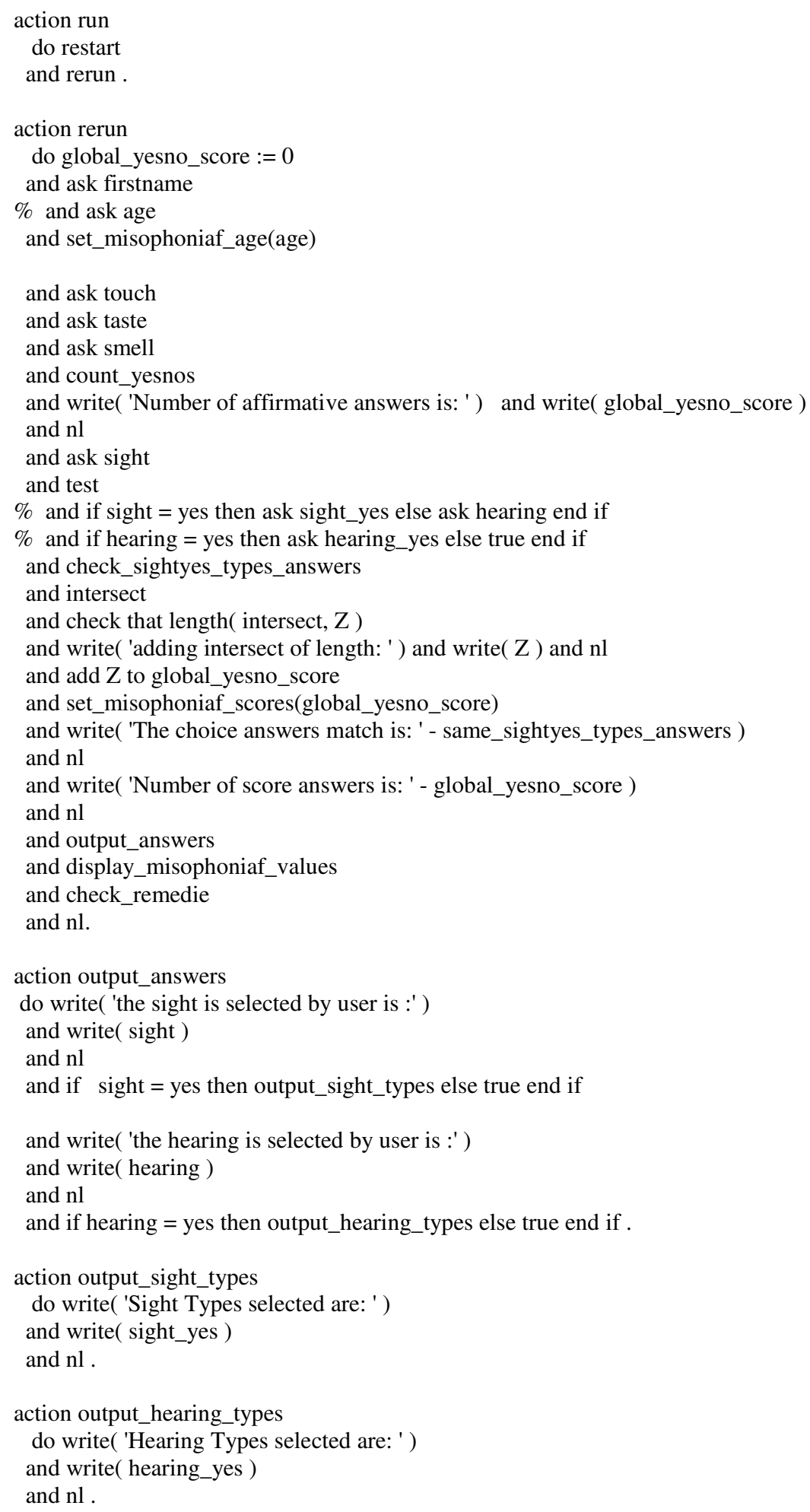




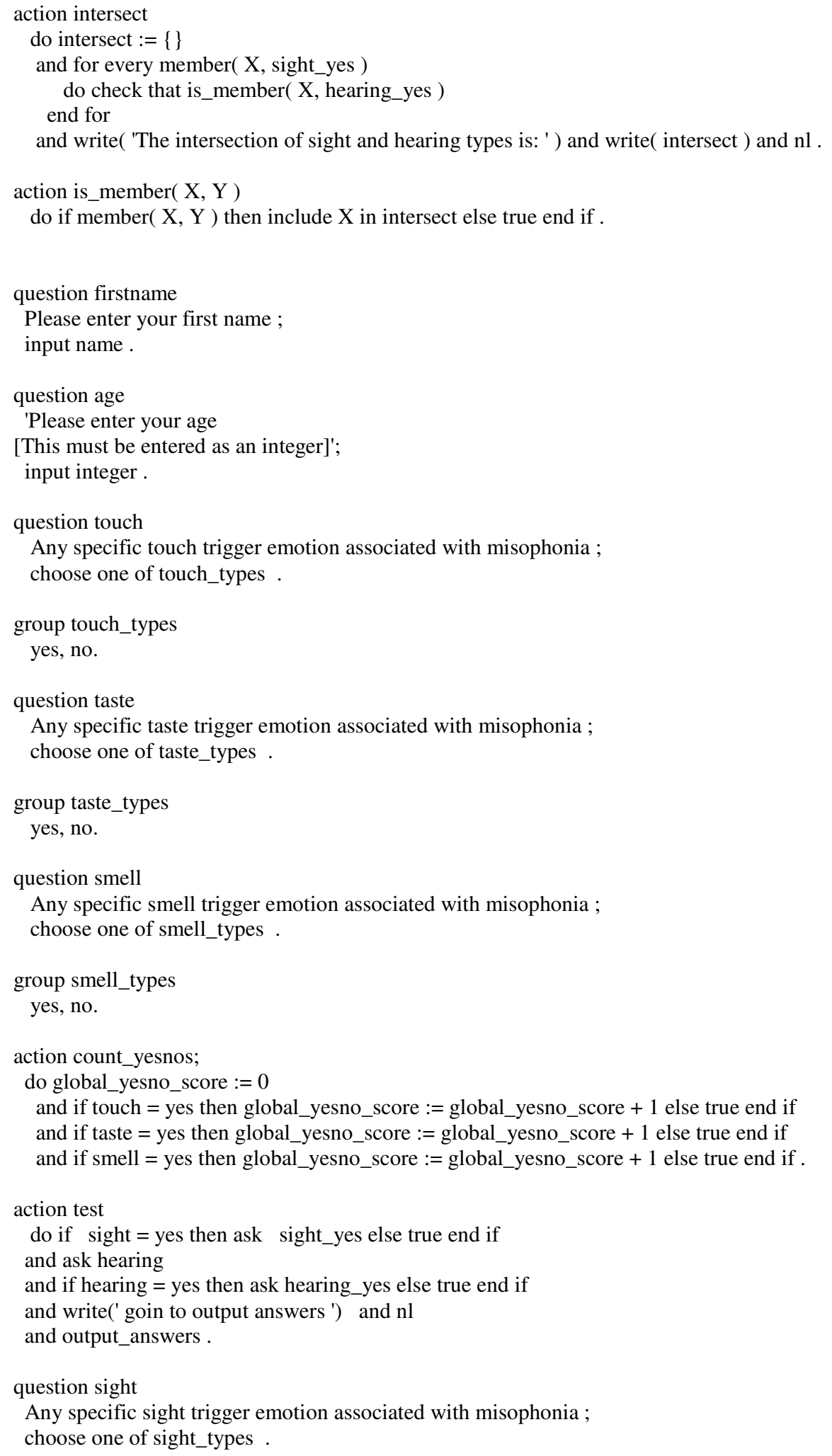


group sight_types

yes, no.

question sight_yes

choose the specific sight trigger emotion associated with misophonia ;

choose some of sightyes_types .

group sightyes_types

'clipping nails ',' brushing teeth ',' eating noise ',' sniffing',' talking',' sneezing',' yawning',' sighing',' walking',' chewing',' laughing',' snoring',' whisteling',' ticking clock',' windshield wipers',' barking dogs',' rocking chairs',' tapping pens',' whispering','noisy neighbour',' tv/ radio',' blinking light',' any_specific sound_not listed' .

question hearing

Any specific hearing trigger emotion associated with misophonia ;

choose one of hearing_types .

group hearing_types

yes, no.

question hearing_yes

choose the specific hearing trigger emotion associated with misophonia ;

choose some of hearingyes_types .

group hearingyes_types

'clipping nails ',' brushing teeth ',' eating noise ',' sniffing',' talking',' sneezing',' yawning',' sighing',' walking',' chewing',' laughing',' snoring',' whisteling',' ticking clock',' windshield wipers',' barking dogs',' rocking chairs',' tapping pens',' whispering','noisy neighbour',' tv/ radio ',' any_specific sound_not listed '.

action check_sightyes_types_answers;

do same_sightyes_types_answers :=false

and if sight $=$ yes and hearing $=$ yes and sight_yes $=$ hearing_yes

then global_yesno_score $:=$ global_yesno_score +1 else true end if

and if sight_yes $=$ hearing_yes then same_sightyes_types_answers $:=$ true else true end if.

$\%$ and if sight_yes $=$ hearing_yes then global_yesno_score $:=$ global_yesno_score +1 else true end if.

fuzzy_variable age;

ranges from 0 to 50 ;

fuzzy_set child is $\backslash$ shaped and linear at 12,16 ;

fuzzy_set teen is $\wedge$ shaped and linear at $15,19,21$;

fuzzy_set adult is $\wedge$ shaped and linear at $20,26,30$;

fuzzy_set average is $\wedge$ shaped and linear at $29,36,40$;

fuzzy_set old is $\wedge$ shaped and linear at $39,45,50$.

fuzzy_variable scores;

ranges from 0 to 27 ;

fuzzy_set marks1 is $\backslash$ shaped and linear at 0,10 ;

fuzzy_set marks 2 is $\wedge$ shaped and linear at $9,11,13$;

fuzzy_set marks3 is $\backslash$ shaped and linear at 14,27 .

fuzzy_variable desiese;

ranges from 0 to 192 ;

fuzzy_set daph is $\backslash$ shaped and linear at 0,30 ;

fuzzy_set aarh is $\wedge$ shaped and linear at $31,40,50$;

fuzzy_set daah is $\wedge$ shaped and linear at $51,60,70$;

fuzzy_set aahd is $\wedge$ shaped and linear at $75,80,85$;

fuzzy_set arah is $\wedge$ shaped and linear at $86,90,95$;

fuzzy_set arhh is $\wedge$ shaped and linear at $96,100,105$;

fuzzy_set dahh is $\Lambda$ shaped and linear at $106,110,115$; 


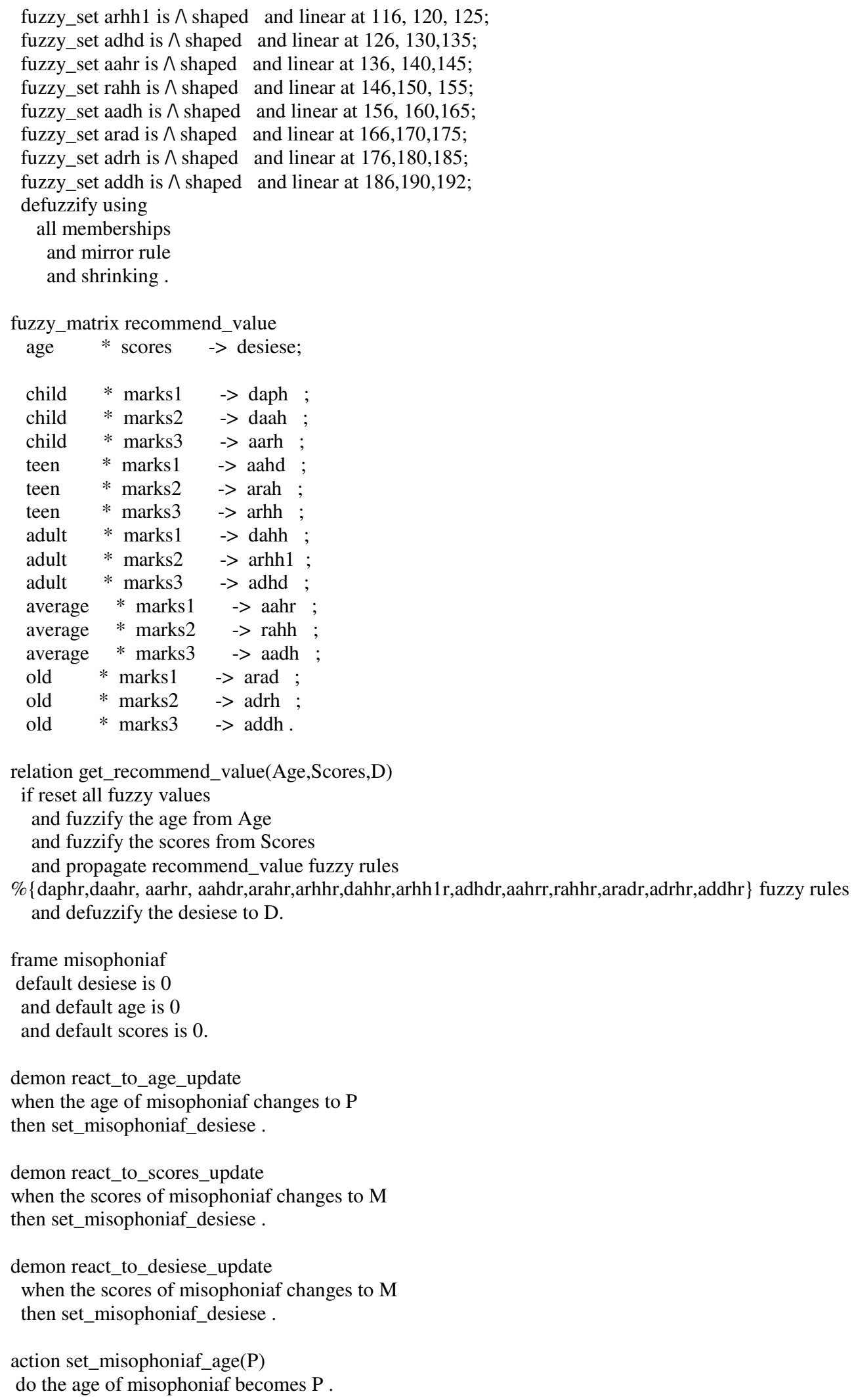




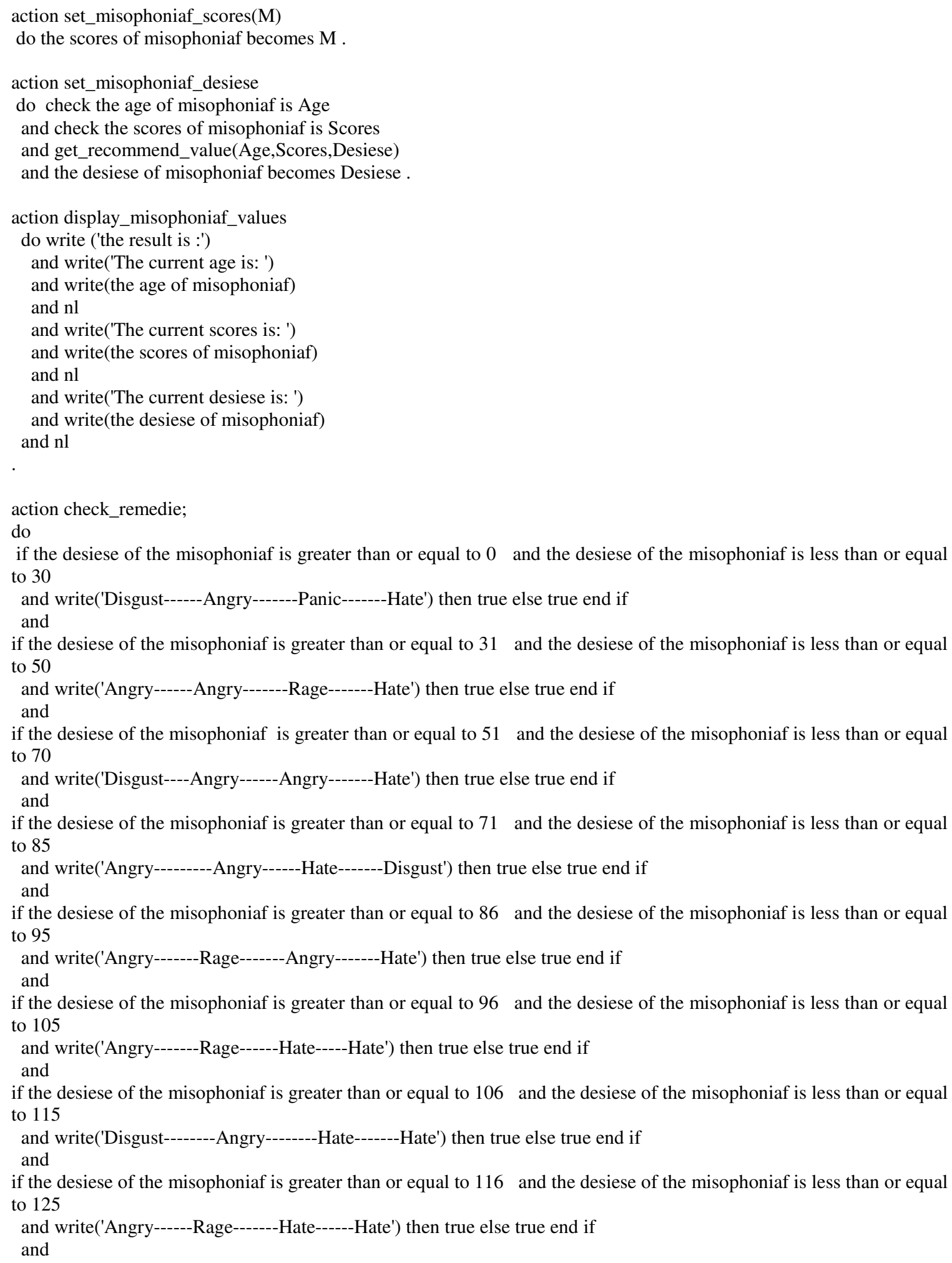


International Journal of Computer Science \& Information Technology (IJCSIT) Vol 9, No 1, February 2017

if the desiese of the misophoniaf is greater than or equal to 126 and the desiese of the misophoniaf is less than or equal to 135

and write('Angry------Disgust-----Hate------Disgust') then true else true end if

and

if the desiese of the misophoniaf is greater than or equal to 136 and the desiese of the misophoniaf is less than or equal to 145

and write('Angry------Angry------Hate------Rage') then true else true end if

and

if the desiese of the misophoniaf is greater than or equal to 146 and the desiese of the misophoniaf is less than or equal to 155

and write('Rage------Angry------Hate------Hate') then true else true end if

and

if the desiese of the misophoniaf is greater than or equal to 156 and the desiese of the misophoniaf is less than or equal to 165

and write('Angry------Angry------Disgust------Hate') then true else true end if

and

if the desiese of the misophoniaf is greater than or equal to 166 and the desiese of the misophoniaf is less than or equal to 175

and write('Angry------Rage-------Anger------Disgust') then true else true end if

and

if the desiese of the misophoniaf is greater than or equal to 176 and the desiese of the misophoniaf is less than or equal to 185

and write('Angry------Disgust------Rage-----Hate') then true else true end if

and

if the desiese of the misophoniaf is greater than or equal to 186 and the desiese of the misophoniaf is less than or equal to 192 and write('Angry---------Disgust------Disgust------Hate') then true else true end if. 